\title{
Carbon-Based Solid Acid as an Efficient and Reusable Catalyst for the Synthesis of 1,8-Dioxodecahydroacridines Under Solvent-Free Conditions
}

\author{
Abolghasem Davoodnia," Amir Khojastehnezhad, and Niloofar Tavakoli-Hoseini \\ Department of Chemistry, Mashhad Branch, Islamic Azad University, Mashhad, Iran. *E-mail: adavoodnia@mshdiau.ac.ir \\ Received April 7, 2011, Accepted May 18, 2011
}

\begin{abstract}
Carbon-based solid acid catalyst was found to be highly efficient, eco-friendly and recyclable heterogeneous catalyst for the multicomponent reaction of dimedone, aromatic aldehydes, and a nitrogen source (ammonium acetate or aromatic amines) under solvent-free conditions, giving rise to 1,8-dioxodecahydroacridines in high yields. The present methodology offers several advantages, such as a simple procedure with an easy work-up, short reaction times, high yields, and the absence of any volatile and hazardous organic solvents.
\end{abstract}

Key Words : Carbon-based solid acid, 1,8-Dioxodecahydroacridines, Solvent-free conditions

\section{Introduction}

Multicomponent reactions (MCRs) have emerged as efficient and powerful tools in modern synthetic organic chemistry because the synthesis of complex organic molecules from simple and readily available substrates can be achieved in a very fast and efficient manner without the isolation of any intermediate. ${ }^{1-4}$ In this type of reactions three or more components are reacted to form ideally one product, which contains the essential parts of all the initial reactants. MCRs contribute to the requirements of an environmentally friendly process by reducing the number of synthetic steps, energy consumption and waste production. Therefore, developing new MCRs and improving known MCRs are popular areas of research in current organic chemistry.

1,4-Dihydropyridines (1,4-DHPs) are a common feature of various bioactive compounds such as vasodilator, bronchodilator, anti-atherosclerotic, anti-cancer and anti-diabetic agents. ${ }^{5-8}$ Also, a number of DHP derivatives are employed as potential drug candidates for the treatment of congestive heart failure. ${ }^{9}$ 1,8-Dioxodecahydroacridines and their derivatives are polyfunctionalized 1,4-dihydropyridine derivatives which have received less attention than other 1,4-dihydropyridine derivatives. These compounds are generally synthesized in a three-component cyclocondensation of dimedone, aromatic aldehydes and ammonium acetate or amines in the presence of several catalysts such as $p$-dodecylbenezenesulfonic acid (DBSA), ${ }^{10}\left[\mathrm{~B}\left(\mathrm{C}_{6} \mathrm{~F}_{5}\right)_{3}\right],{ }^{11}$ Proline, ${ }^{12}$ Amberlyst$15,{ }^{13} \mathrm{NH}_{4} \mathrm{Cl},{ }^{14}$ and Brønsted acidic imidazolium salts. ${ }^{15}$ Synthesis of these compounds by the classical Hantzsch's procedure $^{16}$ or reaction of aldoximes with dimedone, under microwave irradiation have also been reported. ${ }^{17}$ However, most of these reported procedures have disadvantages including low yields, prolonged reaction time, toxic organic solvents and harsh reaction conditions. Therefore, the development of simple, efficient, high-yielding, and environmentally friendly methods under mild conditions using new catalysts for the synthesis of 1,8-dioxodecahydroacridines is still necessary.
Replacement of conventional toxic and pollutant Brønsted and Lewis acid catalysts with environmentally benign and reusable solid heterogeneous catalysts is an active area of current research. Using solid acid catalysts have some advantages such as ease of products separation, recycling of the catalyst and environmental acceptability as compared to liquid acid catalyst. ${ }^{18}$ Carbon-based solid acid (CBSA) catalyst has many advantages. It is insoluble in common organic solvents, causes low corrosion, and shows environmental acceptability. Also the products could be easily separated from the reaction mixture and the catalyst is recoverable without decreasing its activity. Therefore, it can be successfully used instead of sulfuric acid as catalyst. ${ }^{19-22}$ To the best of our knowledge there are no examples on the use of CBSAs as catalysts for the synthesis of 1,8-dioxodecahydroacridines.

Due to our interest in the synthesis of heterocyclic compounds, ${ }^{23-26}$ and in continuation of our previous works on the applications of reusable catalysts in organic reactions, ${ }^{27-35}$ herein we report the new efficient synthesis of 1,8-dioxodecahydroacridines using a CBSA as catalyst (Scheme 1).

\section{Experimental}

All chemicals were available commercially and used without additional purification. The catalyst was synthesized according to the literature. Melting points were recorded on an electrothermal type 9100 melting point apparatus. The IR spectra were obtained using a 4300 Shimadzu spectrophotometer as KBr disks. The ${ }^{1} \mathrm{H}$ NMR (500 MHz) spectra were

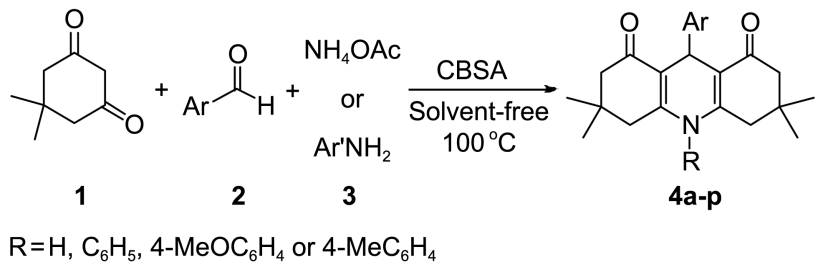

Scheme 1. Synthesis of 1,8-dioxodecahydroacridines catalyzed by CBSA. 
recorded with a Bruker DRX500 spectrometer.

Preparation of CBSA. The CBSA was prepared according to the reported procedure by Hara and co-workers. ${ }^{19}$ Naphthalene (20 g) was heated in concentrated sulfuric acid $(>96 \%, 200 \mathrm{~mL})$ at $250{ }^{\circ} \mathrm{C}$ under a flow of $\mathrm{N}_{2}$. After heating for $15 \mathrm{~h}$, excess sulfuric acid was removed from the dark brown tar by vacuum distillation at $250{ }^{\circ} \mathrm{C}$ for $5 \mathrm{~h}$, which resulted in a black solid. The solid was then ground to a powder and was washed repeatedly in boiling water until impurities such as sulfate ions were no longer detected in the wash water. The density of the $\mathrm{SO}_{3} \mathrm{H}$ group was measured using $\mathrm{NaOH}(0.01 \mathrm{~mol} / \mathrm{L})$ as titrant by acid-base potentiometric titration. The amount of $\mathrm{SO}_{3} \mathrm{H}$ attached to the polycyclic aromatic carbon was $2.79 \mathrm{mmol} / \mathrm{g}$.

General Procedure for the Synthesis of 1,8-Dioxodecahydroacridines 4a-p Catalyzed by CBSA. A mixture of dimedone 1 ( $2 \mathrm{mmol})$, aromatic aldehyde 2 (1 $\mathrm{mmol})$, ammonium acetate or aromatic amines $\mathbf{3}(1 \mathrm{mmol})$, and CBSA $(0.03 \mathrm{~g})$ was heated in the oil bath at $100{ }^{\circ} \mathrm{C}$ for $15-40$ min. During the procedure, the reaction was monitored by TLC. Upon completion, the reaction mixture was cooled to room temperature and hot ethanol was added. The catalyst was insoluble in hot ethanol and it could therefore be recycled by a simple filtration. The product was then collected from the filtrate after cooling to room temperature and recrystallized from ethanol to give compounds $\mathbf{4 a - p}$ in high yields.

Recycling and Reusing of the Catalyst. Due to the fact that the catalyst was insoluble in hot ethanol, it could therefore be recycled by a simple filtration. The separated catalyst was washed with ethanol, dried at $60{ }^{\circ} \mathrm{C}$ under vacuum for $1 \mathrm{~h}$ and was reused in another reaction. The catalyst could be used at least three times without significant loss of activity.

\section{Selected ${ }^{1} \mathrm{H}$ NMR Data.}

3,3,6,6-Tetramethyl-1,8-dioxo-9-(4-chlorophenyl)-decahydroacridine (4d): $\left(500 \mathrm{MHz}, \mathrm{CDCl}_{3}\right) \delta 1.00(\mathrm{~s}, 6 \mathrm{H}$, 2Me), 1.12 (s, 6H, 2Me), 2.19 (d, $J=16.3 \mathrm{~Hz}, 2 \mathrm{H}), 2.27$ (d, $J=16.3 \mathrm{~Hz}, 2 \mathrm{H}), 2.29$ (d, $J=16.7 \mathrm{~Hz}, 2 \mathrm{H}), 2.41$ (d, $J=16.7 \mathrm{~Hz}, 2 \mathrm{H}), 5.07$ (s, 1H, CH), 6.68 (s br., 1H, NH), 7.19 (d, $J=8.4 \mathrm{~Hz}, 2 \mathrm{H}$, arom-H), 7.30 (d, $J=8.4 \mathrm{~Hz}, 2 \mathrm{H}$, arom-H).

3,3,6,6-Tetramethyl-1,8-dioxo-9-(4-nitrophenyl)-decahydroacridine (4h): $\left(500 \mathrm{MHz}, \mathrm{CDCl}_{3}\right) \delta 1.00(\mathrm{~s}, 6 \mathrm{H}$, 2Me), 1.14 (s, 6H, 2Me), 2.19 (d, $J=16.5 \mathrm{~Hz}, 2 \mathrm{H}), 2.28$ $(\mathrm{d}, J=16.5 \mathrm{~Hz}, 2 \mathrm{H}), 2.32(\mathrm{~d}, J=16.7 \mathrm{~Hz}, 2 \mathrm{H}), 2.46$ (d, $J=16.7 \mathrm{~Hz}, 2 \mathrm{H}), 5.19$ (s, 1H, CH), 6.12 (s br., 1H, NH), $7.54(\mathrm{~d}, J=8.7 \mathrm{~Hz}, 2 \mathrm{H}$, arom-H), 8.10 (d, $J=8.7 \mathrm{~Hz}, 2 \mathrm{H}$, arom-H).

3,3,6,6-Tetramethyl-1,8-dioxo-9-(4-chlorophenyl)-10(4-methylphenyl)-decahydroacridine (4I): $(500 \mathrm{MHz}$, $\left.\mathrm{CDCl}_{3}\right) \delta 0.83(\mathrm{~s}, 6 \mathrm{H}, 2 \mathrm{Me}), 0.97(\mathrm{~s}, 6 \mathrm{H}, 2 \mathrm{Me}), 1.86(\mathrm{~d}, J=$ $17.4 \mathrm{~Hz}, 2 \mathrm{H}), 2.09$ (d, $J=17.4 \mathrm{~Hz}, 2 \mathrm{H}), 2.15(\mathrm{~d}, J=16.5 \mathrm{~Hz}$, $2 \mathrm{H}), 2.22(\mathrm{~d}, J=16.5 \mathrm{~Hz}, 2 \mathrm{H}), 2.52(\mathrm{~s}, 3 \mathrm{H}, \mathrm{Me}), 5.27(\mathrm{~s}, 1 \mathrm{H}$, $\mathrm{CH}), 7.11(\mathrm{~d}, J=8.3 \mathrm{~Hz}, 2 \mathrm{H}$, arom-H), $7.24(\mathrm{~d}, J=8.3 \mathrm{~Hz}$, 2H, arom-H), 7.37 (d, $J=8.7 \mathrm{~Hz}, 2 \mathrm{H}$, arom-H), 7.39 (d, $J=$ $8.7 \mathrm{~Hz}, 2 \mathrm{H}$, arom-H).

\section{Results and Discussion}

The one-pot synthesis of 1,8-dioxodecahydroacridines was achieved by the three-component condensation of dimedone, aromatic aldehydes, and ammonium acetate or aromatic amines in the presence of CBSA as a heterogeneous catalyst (Scheme 1). CBSA was prepared according to the literature procedure. ${ }^{19}$ At first, the synthesis of compound $4 \mathbf{a}$ was selected as a model reaction to optimize the reaction conditions. The reaction was carried out by heating a mixture of dimedone $(2 \mathrm{mmol})$, benzaldehyde $(1 \mathrm{mmol})$, and ammonium acetate $(1 \mathrm{mmol})$ under various conditions.

The efficiency of the reaction is affected mainly by the amount of CBSA (Table 1). No product was obtained in the absence of the catalyst even after 180 min (entry 1) indicating that the catalyst is necessary for the reaction. Increasing the amount of the catalyst increased the yield of the product 4a. The optimal amount of CBSA was 0.03 g (entry 4); increasing the amount of the catalyst beyond this value did not increase the yield noticeably (entries 5, 6).

Furthermore, the reaction was carried out in different solvents and under solvent-free conditions. As shown in Table 2, the yields of the reaction under solvent-free conditions were greater and the reaction times were generally shorter than the conventional methods. The best result was obtained at 100 ${ }^{\circ} \mathrm{C}$ for $20 \mathrm{~min}$ under solvent-free conditions. Increasing the reaction time or temperature did not improve the yield.

Table 1. Effect of the amounts of CBSA on the model reaction ${ }^{a}$

\begin{tabular}{cccc}
\hline Entry & Catalyst $(\mathrm{g})$ & Time $(\mathrm{min})$ & ${\text { Yield }(\%)^{b}}^{b}$ \\
\hline 1 & None & 180 & None \\
2 & 0.01 & 30 & 65 \\
3 & 0.02 & 30 & 84 \\
4 & 0.03 & 20 & 93 \\
5 & 0.05 & 20 & 93 \\
6 & 0.10 & 40 & 95 \\
\hline
\end{tabular}

${ }^{a}$ Reaction conditions: dimedone $(2 \mathrm{mmol})$, benzaldehyde $(1 \mathrm{mmol})$, and ammonium acetate $(1 \mathrm{mmol})$ at $100{ }^{\circ} \mathrm{C} .{ }^{b}$ Isolated yields.

Table 2. Synthesis of compound $\mathbf{4 a}$ in the presence of CBSA ( 0.03 g) in different solvents ${ }^{a}$

\begin{tabular}{ccccc}
\hline Entry & Solvent & Temperature $\left({ }^{\circ} \mathrm{C}\right)$ & Time $(\mathrm{h})$ & Yield $(\%)^{b}$ \\
\hline 1 & EtOH & Reflux & 5 & 85 \\
2 & $\mathrm{MeOH}$ & Reflux & 5 & 75 \\
3 & $\mathrm{H}_{2} \mathrm{O}$ & Reflux & 5 & 72 \\
4 & $\mathrm{CH}_{3} \mathrm{CN}$ & Reflux & 5 & 65 \\
5 & $\mathrm{CH}_{2} \mathrm{Cl}_{2}$ & Reflux & 5 & Trace \\
6 & Solvent-Free & 70 & $30(\mathrm{~min})$ & 62 \\
7 & Solvent-Free & 80 & $30(\mathrm{~min})$ & 75 \\
8 & Solvent-Free & 90 & $20(\mathrm{~min})$ & 83 \\
9 & Solvent-Free & 100 & $20(\mathrm{~min})$ & 93 \\
10 & Solvent-Free & 110 & $20(\mathrm{~min})$ & 93 \\
11 & Solvent-Free & 120 & $20(\mathrm{~min})$ & 94
\end{tabular}

Reaction conditions: dimedone $(2 \mathrm{mmol})$, benzaldehyde $(1 \mathrm{mmol})$, and ammonium acetate $(1 \mathrm{mmol}) .{ }^{b}$ Isolated yields. 
Table 3. Preparation of 1,8-dioxodecahydroacridines 4a-p using CBSA ( 0.03 g) as catalyst ${ }^{a}$

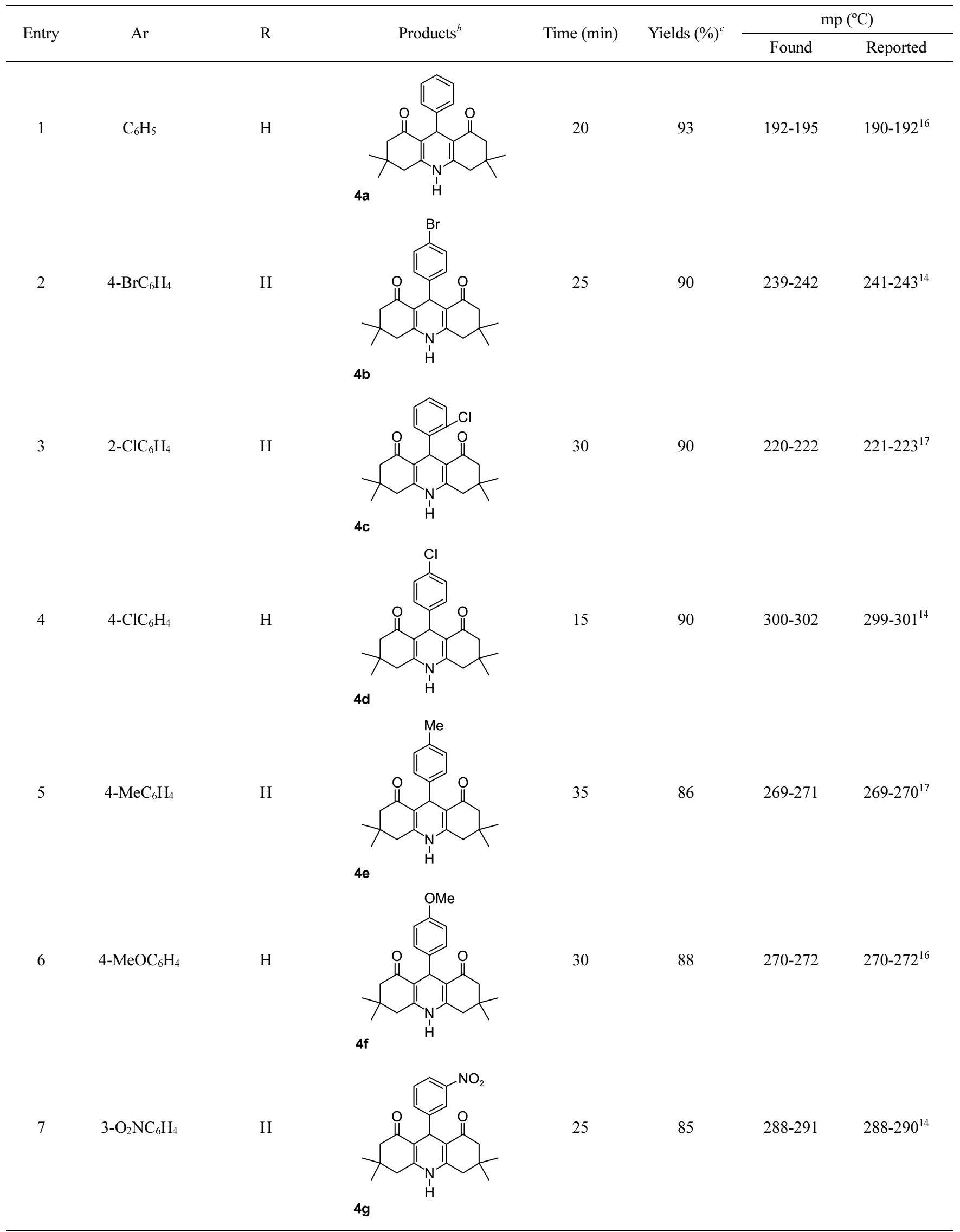


Table 3. Continued

\begin{tabular}{|c|c|c|c|c|c|c|c|}
\hline \multirow{2}{*}{ Entry } & \multirow{2}{*}{$\mathrm{Ar}$} & \multirow{2}{*}{$\mathrm{R}$} & \multirow{2}{*}{ Products $^{b}$} & \multirow{2}{*}{ Time (min) } & \multirow{2}{*}{ Yields $(\%)^{c}$} & \multicolumn{2}{|c|}{$\mathrm{mp}\left({ }^{\circ} \mathrm{C}\right)$} \\
\hline & & & & & & Found & Reported \\
\hline 8 & $4-\mathrm{O}_{2} \mathrm{NC}_{6} \mathrm{H}_{4}$ & $\mathrm{H}$ & & 15 & 92 & $286-289$ & $286-288^{14}$ \\
\hline 9 & $\mathrm{C}_{6} \mathrm{H}_{5}$ & $\mathrm{C}_{6} \mathrm{H}_{5}$ & & 30 & 84 & $252-255$ & $254-256^{13}$ \\
\hline 10 & $\mathrm{C}_{6} \mathrm{H}_{5}$ & 4- $\mathrm{MeC}_{6} \mathrm{H}_{4}$ & & 35 & 85 & $260-263$ & $260-262^{15}$ \\
\hline 11 & 4- $\mathrm{ClC}_{6} \mathrm{H}_{4}$ & $4-\mathrm{MeOC}_{6} \mathrm{H}_{4}$ & & 30 & 88 & $250-252$ & $251-252^{15}$ \\
\hline 12 & $4-\mathrm{ClC}_{6} \mathrm{H}_{4}$ & 4- $\mathrm{MeC}_{6} \mathrm{H}_{4}$ & & 30 & 88 & $270-271$ & $269-271^{15}$ \\
\hline 13 & $4-\mathrm{MeOC}_{6} \mathrm{H}_{4}$ & $\mathrm{C}_{6} \mathrm{H}_{5}$ & & 40 & 81 & $220-222$ & $220-222^{13}$ \\
\hline
\end{tabular}


Table 3. Contiued

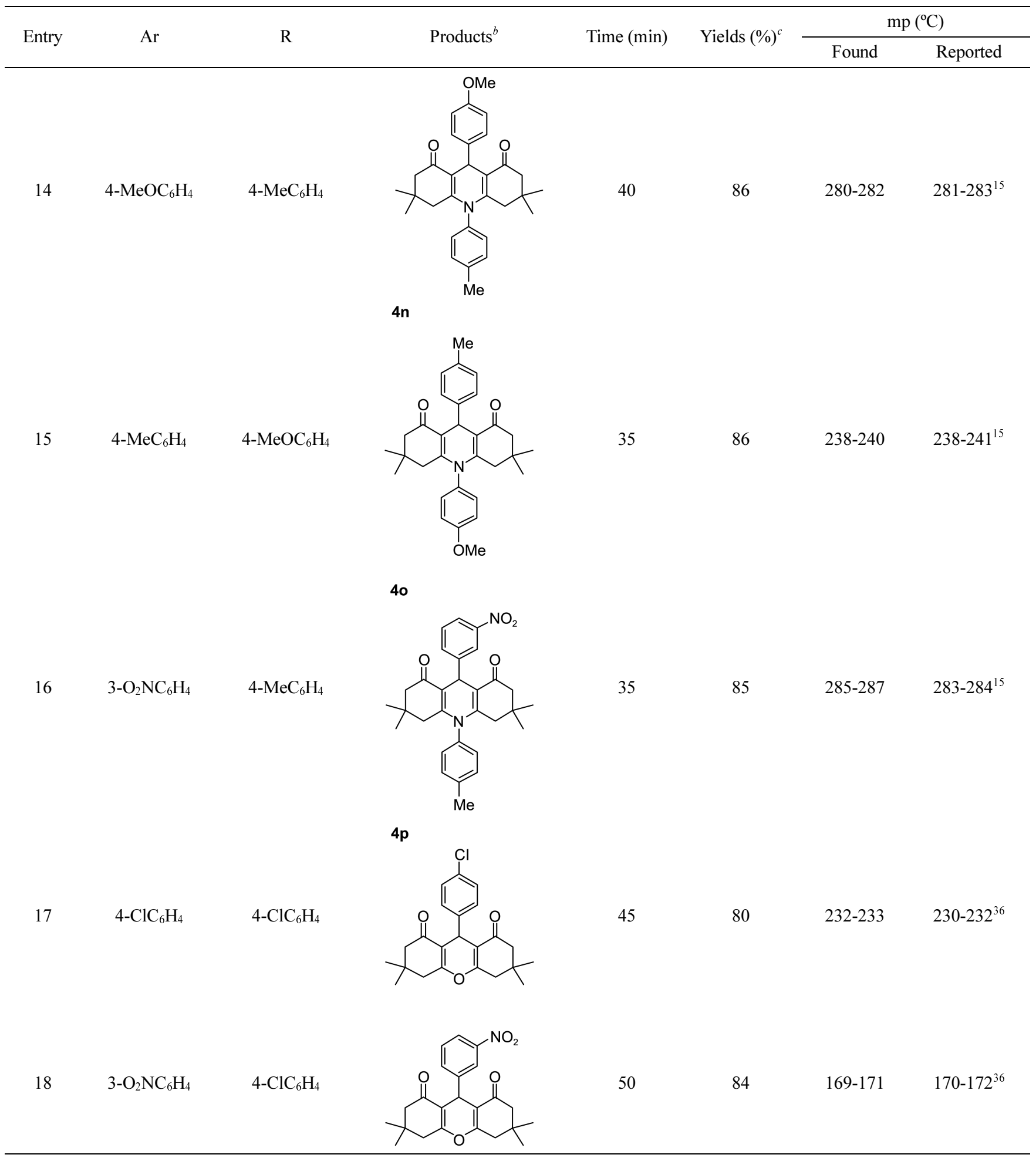

${ }^{a}$ Reaction conditions: dimedone $(2 \mathrm{mmol})$, aromatic aldehyde $(1 \mathrm{mmol})$, and ammonium acetate or aromatic amine $(1 \mathrm{mmol})$ at $100{ }^{\circ} \mathrm{C}$ under solventfree conditions. ${ }^{b}$ All the products were characterized by IR spectral data and comparision of their melting points with those of authentic samples. Also, the structures of some products were confirmed by ${ }^{1} \mathrm{H}$ NMR spectral data. ${ }^{c}$ Isolated yields.

Subsequently, therefore, all reactions were carried out at 100 ${ }^{\circ} \mathrm{C}$ in the presence of CBSA $(0.03 \mathrm{~g})$ under solvent-free conditions.

Using these optimized reaction conditions, the scope and efficiency of this approach was explored for the synthesis of a wide variety of 1,8-dioxodecahydroacridines and the obtained results are summarized in Table 3. Aromatic amines substituted with electron-donating group or none reacted successfully with dimedone and a wide range of aromatic aldehydes bearing both electron-donating and electron-with- 


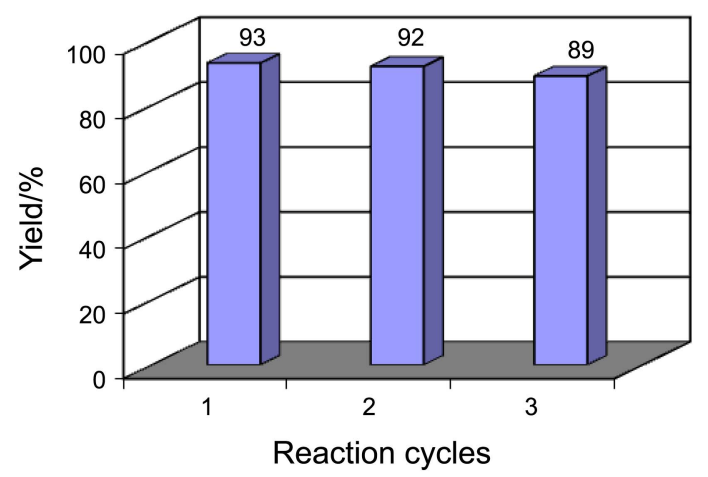

Figure 1. Reusability of the catalyst for model reaction.

drawing substituents and gave the products 1,8-dioxodecahydroacridines in high yields. However, when the mixture of aromatic amines substituted with electron-withdrawing group, dimedone and aromatic aldehydes was heated under optimized reaction conditions, 1,8-dioxooctahydroxanthenes ${ }^{36}$ were formed (Table 3, entries 17 and 18). Based on Wang's report, ${ }^{15}$ aromatic amines substituted with electron-withdrawing group did not have enough nucleophilicity to produce 1,8-dioxodecahydroacridines.

Reusability of the catalyst was also investigated. For this purpose, the same model reaction was again studied under optimized conditions. After the completion of the reaction, the reaction mixture was cooled to room temperature, and hot ethanol was added. The catalyst was separated by simple filtration, dried at $60{ }^{\circ} \mathrm{C}$ under vacuum for $1 \mathrm{~h}$, and reused for a similar reaction. As shown in Figure 1, the catalyst could be reused at least three times without significant loss of activity.

In conclusion, we have reported a simple new catalytic method for the synthesis of 1,8-dioxodecahydroacridines by one-pot three-component reaction of dimedone, aromatic aldehydes, and ammonium acetate or aromatic amines using CBSA as an efficient, reusable, and green heterogeneous catalyst. The catalyst can be recycled after a simple work-up, and used at least three times without substantial reduction in its catalytic activity. High yields, short reaction times and easy work-up are just a few of the advantages of this procedure.

Acknowledgments. The authors are thankful to Islamic Azad University, Mashhad Branch for financial support.

\section{References}

1. Zhu, J., Bienayme, H., Eds.; Wiley-VCH: Weinheim, Germany, 2005.

2. Bagley, M. C.; Lubinu, M. C. Top. Heterocycl. Chem. 2006, 31.

3. Simon, C.; Constantieux, T.; Rodriguez, J. Eur. J. Org. Chem. 2004, 4957.
4. Dömling, A.; Ugi, I. Andew. Chem., Int. Ed. 2000, 39, 3168.

5. Gordeev, M. F.; Patel, D. V.; Gordon, E. M. J. Org. Chem. 1996, 61, 924.

6. Sausins, A.; Duburs, G. Heterocycles 1988, 27, 269.

7. Coburn, R. A.; Wierzba, M.; Suto, M. J.; Solo, A. J.; Triggle, A. M.; Triggle, D. J. J. Med. Chem. 1988, 31, 2103.

8. Godfraind, T.; Miller, R.; Wibo, M. Pharmacol. Rev. 1986, 38, 321.

9. Vo, D.; Matowe, W. C.; Ramesh, M.; Iqbal, N.; Wolowyk, M. W.; Howlett, S. E.; Knaus, E. E. J. Med. Chem. 1995, 38, 2851.

10. Jin, T. S.; Zhang, J. S.; Guo, T. T.; Wang, A. Q.; Li, T. S. Synthesis 2004, 12, 2001.

11. Chandrasekhar, S.; Rao, Y. S.; Sreelakshmi, L.; Mahipal, B.; Reddy, C. R. Synthesis 2008, 11, 1737.

12. Venkatesan, K.; Pujari, S. S.; Srinivasan, K. V. Synth. Commun. 2009, 39, 228.

13. Das, B.; Thirupathi, P.; Mahender, I.; Saidi Reddy, V.; Rao, Y. K. J. Mol. Catal. A: Chem. 2006, 247, 233.

14. Balalaie, S.; Chadegani, F.; Darviche, F.; Bijanzadeh, H. R. Chin. J. Chem. 2009, 27, 1953.

15. Shen, W.; Wang, L. M.; Tian, H.; Tang, J.; Yu, J. J. J. Fluorine Chem. 2009, 130, 522.

16. Mora, A.; Suarez, M.; Ochoa, E.; Morales, A.; del Bosque, J. R. J. Heterocycl. Chem. 1995, 32, 235.

17. Tu, S.; Miao, C.; Gao, Y.; Fang, F.; Zhuang, Q.; Feng, Y.; Shia, D. Synlett 2004, 2, 255.

18. Okuhara, T. Chem. Rev. 2002, 102, 3641.

19. Hara, M.; Yoshida, T.; Takagaki, A.; Takata, T.; Kondo, J. N.; Hayashi, S.; Domen, K. Angew. Chem., Int. Ed. 2004, 43, 2955.

20. Okamura, M.; Takagaki, A.; Toda, M.; Kondo, J. N.; Domen, K.; Tatsumi, T.; Hara, M.; Hayashi, S. Chem. Mater. 2006, 18, 3039.

21. Zali, A.; Shokrolahi, A.; Keshavarz, M. H.; Zarei, M. A. Acta Chim. Slov. 2008, 55, 257.

22. Zhou, L.; Liu, K.; Hua, W. M.; Yue, Y. H.; Gao, Z. Chin. J. Chem. 2009, 30, 196.

23. Rahimizadeh, M.; Davoodnia, A.; Heravi, M. M.; Bakavoli, M. Phosphorus, Sulfur Silicon Relat. Elem. 2002, 177, 2923.

24. Bakavoli, M.; Davoodnia, A.; Rahimizadeh, M.; Heravi, M. M. Mendeleev Commun. 2006, 1, 29.

25. Davoodnia, A.; Bakavoli, M.; Pooryaghoobi, N.; Roshani, M. Heterocycl. Commun. 2007, 13, 323.

26. Davoodnia, A.; Roshani, M.; Saleh-Nadim, E.; Bakavoli, M.; Tavakoli-Hoseini, N. Chin. Chem. Lett. 2007, 18, 1327.

27. Davoodnia, A.; Bakavoli, M.; Barakouhi, Gh.; Tavakoli-Hoseini, N. Chin. Chem. Lett. 2007, 18, 1483.

28. Davoodnia, A.; Roshani, M.; Malaeke, S. H.; Bakavoli, M. Chin. Chem. Lett. 2008, 19, 525.

29. Davoodnia, A.; Heravi, M. M.; Rezaei-Daghigh, L.; TavakoliHoseini, N. Monatsh. Chem. 2009, 140, 1499.

30. Davoodnia, A.; Bakavoli, M.; Moloudi, R.; Khashi, M.; TavakoliHoseini, N. Monatsh. Chem. 2010, 141, 867.

31. Davoodnia, A.; Heravi, M. M.; Safavi-Rad, Z.; Tavakoli-Hoseini, N. Synth. Commun. 2010, 40, 2588.

32. Tavakoli-Hoseini, N.; Davoodnia, A. Asian J. Chem. 2010, 22, 7197.

33. Davoodnia, A.; Allameh, S.; Fakhari, A. R.; Tavakoli-Hoseini, N. Chin. Chem. Lett. 2010, 21, 550.

34. Davoodnia, A.; Bakavoli, M.; Moloudi, R.; Khashi, M.; TavakoliHoseini, N. Chin. Chem. Lett. 2010, 21, 1.

35. Davoodnia, A. Asian J. Chem. 2010, 22, 1595.

36. Niknam, K.; Panahi, F.; Saberi, D.; Mohagheghnejad, M. J. Heterocycl. Chem. 2010, 47, 292. 